\title{
Enhanced near-infrared absorption for laser powder bed fusion using reduced graphene oxide
}

\author{
Chu Lun Alex Leung ${ }^{\mathrm{a}, \mathrm{b}, 1, *}$, Iuliia Elizarova ${ }^{\mathrm{c}, 1, *}$, Mark Isaacs $^{\mathrm{b}, \mathrm{d}}$, Shashidhara Marathe ${ }^{\mathrm{e}}$, \\ Eduardo Saiz ${ }^{\mathrm{c}, *}$, Peter D. Lee ${ }^{\mathrm{a}, \mathrm{b}, *}$ \\ a Department of Mechanical Engineering, University College London, Torrington Place, London WC1E 7JE, United Kingdom \\ ${ }^{\mathrm{b}}$ Research Complex at Harwell, Rutherford Appleton Laboratory, Harwell, Oxfordshire OX11 OFA, Oxon, United Kingdom \\ ${ }^{c}$ Department of Materials, Imperial College London, South Kensington Campus, London SW7 2AZ, United Kingdom \\ ${ }^{\mathrm{d}}$ Department of Chemistry, University College London, 20 Gordon Street, Bloomsbury, London WC1H 0AJ, United Kingdom \\ e Diamond Light Source Ltd, Harwell Science \& Innovation Campus, Oxfordshire, OX11 ODE, United Kingdom
}

\section{A R T I C L E I N F O}

\section{Article history:}

Received 22 December 2020

Revised 19 February 2021

Accepted 13 March 2021

\section{Keywords:}

Absorption

Additive manufacturing

Defects

Consolidation

X-ray imaging

\begin{abstract}
A B S T R A C T
Laser powder bed fusion (LPBF) is a revolutionary manufacturing technology that fabricates parts with unparalleled complexity, layer-by-layer. However, there are limited choices of commercial powders for LPBF, constrained partly by the laser absorbance, an area that is not well investigated. Carbon additives are commonly used to promote near infra-red (NIR) absorbance of the powders but their efficiency is limited. Here, we combine operando synchrotron X-ray imaging with chemical characterisation techniques to elucidate the role of additives on NIR absorption, melt track and defect evolution mechanisms during LPBF. We employ a reduced graphene oxide ( $\mathrm{rGO}$ ) additive to enable LPBF of low NIR absorbance powder, $\mathrm{SiO}_{2}$, under systematic build conditions. This work successfully manufactured glass tracks with a high relative density (99.6\%) and overhang features (> $5 \mathrm{~mm}$ long) without pre/post heat treatment. Compared to conventional carbon additives, the rGO increases the powder's NIR absorbance by ca. 3 times and decreases the warpage and porosity in LPBF glass tracks. Our approach will dramatically widen the palette of materials for laser processing and enable existing LPBF machines to process low absorbance powder, such as $\mathrm{SiO}_{2}$, using a NIR beam.
\end{abstract}

(c) 2021 The Authors. Published by Elsevier Ltd.

This is an open access article under the CC BY license (http://creativecommons.org/licenses/by/4.0/)

\section{Introduction}

Additive manufacturing (AM) shifts the paradigm in materials design and processing, impacting on many different sectors [1], including aerospace [2], biomedical, and tissue engineering [3,4]. It enables the rapid development of products with complex and customisable features made out of various classes of materials, including metals/alloys [5], polymers [6], ceramics [7], glass [8], biomaterials [9], and multi-materials [10]. From the myriad of AM processes developed, laser powder bed fusion (LPBF) is emerging as one of the most promising technologies that employs a laser beam to induce localised melting of powder particles, following a slice by slice digital design. One of the many advantages of LPBF is the

\footnotetext{
* Corresponding authors.

E-mail addresses:
}

i.elizarova14@imperial.ac.uk peter.lee@ucl.ac.uk (P.D. Lee).

alex.leung@ucl.ac.uk（C.L.A. Leung),

1 Joint first author - equal contribution. fabrication of parts in a single step without subsequent lengthy debinding or sintering post processing.

Most commercial LPBF systems are designed to process metallic powders with a near infra-red (NIR) laser beam at wavelengths, $\lambda$, of $1030-1070 \mathrm{~nm}$ [11], with a few systems equipped with a $\mathrm{CO}_{2}$ $(\lambda=10.6 \mu \mathrm{m})$ laser for processing polymers [12] and glass [13-15]. NIR diode lasers are more cost-effective and compact, therefore there is a drive to develop a single LPBF system that can process all classes of materials; however, this has not been realised. One of the main challenges in achieving this is the large variations of laser absorbance $(A)$ in powder feedstocks [11], e.g. metals/alloys $(A=0.53-0.81)$ [16], polymers $(A=0.07-0.52)$ [17], glass $(A \leq 0.03)[15,18]$, and ceramics, such as alumina $(A=0.01-0.3$ [19]) and zirconia $(A \leq 0.15)[20]$ in the NIR region whereas polymers and glasses absorb at least $40 \%$ better at the far-IR spectrum $[21,22]$. The $A$ is considered as a key factor that controls the melt pool and defect dynamics in LPBF [23]. It is governed by the powder chemistry [23], powder packing density [24], and the processing temperature which depends on the input laser parameters, e.g. 
scan speed, and laser power [16,25], etc. Powders with low A (i.e. high transmissivity or/and high reflectivity), e.g. fused silica, usually exhibit weak laser-matter interaction meaning reduced productivity which limits their usage and hampers the adoption of LPBF for new product applications.

There are two alternatives to widen the palette of materials for LPBF technology. Indirect selective laser sintering [26] is used to form a green preform by melting an inorganic material with a lowtemperature organic binder, e.g. polymer [27]. The binder is subsequently removed by post heat treatments whilst consolidating the part [26]. The part often suffers from volume shrinkage that can result in defect formation, compromising its dimensional accuracy and performance. The second method is to employ additives to increase $A$ of the powder feedstock, inducing a photothermal effect to promote the melting or sintering of the inorganic materials.

Materials exhibiting a photothermal effect are used in many applications including welding [28], photothermal therapy, drug delivery, ultra-sound molecular imaging, etc. [29]. These materials include $\mathrm{TiB}_{2}$ [30,31], transition metal oxides (TMOs), e.g. ITO, $\mathrm{TiO}_{2}, \mathrm{Fe}_{2} \mathrm{O}_{3}$, etc. $[32,33]$, and carbon-based materials, e.g., carbon black [34], carbon nanotubes (CNT) [35], graphene [36], reduced graphene oxide [37], and nanocomposites of rGO with additions of mesoporous silicon, amorphous carbon, CuS, [38] or TMOs [39] but their photothermal conversion efficiency is not optimal in the NIR region, e.g. 1030-1070 $\mathrm{nm}$. The use of the photothermal effect in additive manufacturing has been very limited. To date, only carbon powder has been used as a NIR enhancer for LPBF of silica [40]. This application remains less explored, possibly due to the low photothermal conversion efficiency and lack of understanding regarding the interactions with the laser beam during LPBF. Increasing the absorbance of the powder feedstock would enable a significant expansion in AM materials selection and enable single step processing with a LPBF system.

Besides the challenges of selective laser absorbance, one of the major issues hampering the progress of AM technology is our lack of fundamental knowledge of the process. Although recent work is providing much needed insight on the evolution of metallic powder beds during their interaction with the laser beam $[18,23,25,33,41-43]$ using in situ and operando X-ray imaging and diffraction, we know much less when it comes to LPBF of ceramics or glasses [18] because of their fundamental differences in powder properties, e.g. optical, chemical, and thermophysical properties.

Silica glass is a ubiquitous material and has extensive uses across many sectors as it is inexpensive and vastly abundant on earth and other planets [44]. Custom shaped silica glass is usually cast in moulds, made by subtractive manufacturing, or by glass blowing techniques, etc. [15]; however, these methods cannot achieve rapid and economic design iterations, restricting further uses of fused silica. With the advantages of LPBF, several groups exploit this technology to make custom-built optical components, microfluidic ships [8], chemical/environmental sensing applications [45,46]. LPBF can tackle this manufacturing challenge, though little research has been done on LPBF of fused silica with a NIR laser beam. Prior attempts were made to additive manufacture fused silica using a $\mathrm{CO}_{2}$ laser, including the filamentfed directed energy deposition and LPBF wherein the print resolution in both AM technologies was typically in the hundreds of micrometres owing to the large feedstock size [21] and large beam diameter [40], respectively. Additionally, the LPBF parts usually have low-density because they contain various types of imperfections, including porosity [40] and cracks [47]. Other AM approaches, e.g. stereolithography (SLA) [8] and direct ink writing [48], have successfully produced transparent and amorphous fused silica parts, however, both require lengthy post processes, including drying, debinding, and sintering, that limit final part size.
In this work, we employ two different carbon additives: nanocarbon (nano-C) and reduced graphene oxides ( $\mathrm{rGO}$ ) to enhance the laser absorbance of the fused silica powder bed. We process these powder mixtures using a custom-built In Situ and Operando Process Replicator (ISOPR) machine [43] while performing synchrotron X-ray imaging to investigate the role played by these carbon additives and elucidate key mechanisms involved during LPBF of glass. Here, we successfully demonstrate a one-step process of fused silica using LPBF with a NIR beam, achieving high density AM glass parts prior to further heat treatment.

\section{Results and discussion}

\subsection{Materials synthesis and processing}

In this study, we compare the performance of two carbon-based NIR absorbers: (1) nano-carbon (nano-C) and (2) reduced graphene oxide (rGO), investigating how they enhance the processability of low laser absorbance materials, e.g. $\mathrm{SiO}_{2}(A<0.05)$, for LPBF. We produced two powder mixtures of $\mathrm{SiO}_{2}+0.2$ wt.\% nano- $\mathrm{C}$ and $\mathrm{SiO}_{2}+0.2$ wt.\% $\mathrm{rGO}$ via the processing methods depicted in Materials and Methods and Fig. 1a. After that, they were processed using the ISOPR (Fig. 1b). We produced single-layer tracks and larger cubic samples of $5 \times 5 \times 5 \mathrm{~mm}^{3}$ (Fig. 1c). Preliminary characterisation data for the larger samples is available in the Supplementary Information.

\subsection{In situ observations during laser powder bed fusion}

To understand how the selected NIR absorbers perform during LPBF, we conducted a systematic set of single-layer track experiments whilst monitoring the sintering, melting, and vitrification behaviour during LPBF of $\mathrm{SiO}_{2}+$ nano-C and $\mathrm{SiO}_{2}+\mathrm{rGO}$ using high-speed X-ray imaging (Fig. 2a). From these experiments, we selected two sets of time-series radiographs taken during LPBF of $\mathrm{SiO}_{2}+$ nano-C (Fig. 2b,c) and $\mathrm{SiO}_{2}+$ rGO (Fig. 2d,e) at a scan speed, $v=25$ and $50 \mathrm{~mm} \mathrm{~s}^{-1}$ to elucidate aspects of the LPBF process, see details in Supplementary videos 1-4.

Fig. $2 \mathbf{b}$ shows that an intense laser beam $\left(\mathrm{ca} .10^{7} \mathrm{~W} \mathrm{~cm}^{-2}\right)$ penetrates through the powder bed containing $\mathrm{SiO}_{2}+$ nano-C. Some of the NIR beam is absorbed by the nano- $\mathrm{C}$ additive and other photons are either transmitted through or scattered by the $\mathrm{SiO}_{2}$ particles. Upon photon absorption, the NIR beam energy is converted into heat by the photothermal effect which conducts to the rest of the powder bed and promotes sintering or melting of particles. This whole series of phenomena can be described by the radiation conduction mechanism [18].

During the first $100 \mathrm{~ms}$ of the LPBF process, Supplementary video 1 shows that the ejection of powder particles, i.e. powder spatter, mainly occurs at the laser-matter interaction zone whilst forming a cavity (or a denudation zone) in the powder bed. The denudation zone is much larger than those observed during LPBF of metal powders [18,33,41], or for 13-93 bioactive glass [18], see Supplementary Figure 1. This can be linked to the slow acceleration of the laser scanning mirrors, resulting in a long laser-matter interaction time (ca. $5 \mathrm{~ms}$ ). Consequently, the laser beam penetrates through the powder bed and vaporises the metallic substrate ( $3 \mathrm{~mm}$ below powder bed surface), forming a fast-moving plume. Furthermore, there are several factors that may also contribute to the spatter formation mechanism. Firstly, the chemical constituents of the $\mathrm{SiO}_{2}$ powder mixture have low temperature volatile TMOs, e.g. ZnO [49] and $\mathrm{Cr}_{2} \mathrm{O}_{3}$ [50] (Supplementary Table 1), high contents of carbon and oxygen species, and residual moisture. During processing, the low-temperature volatiles can easily vaporise, releasing a small amount of vapour. Secondly, the carbon species can react with $\mathrm{SiO}_{2}$ at $1600{ }^{\circ} \mathrm{C}$ in an inert atmosphere, 


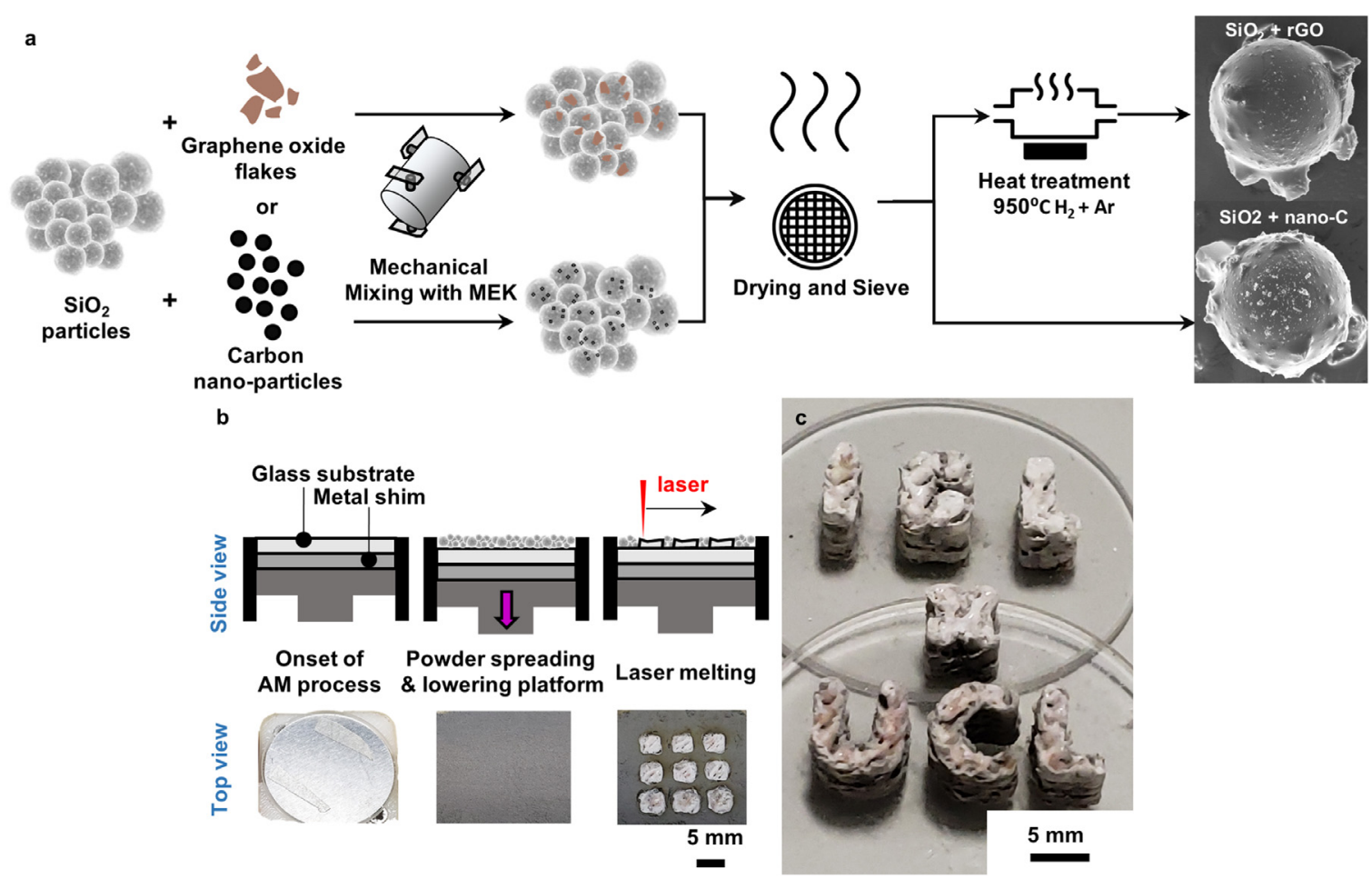

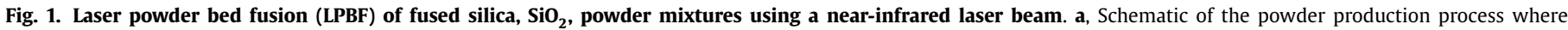

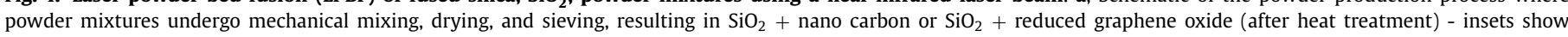

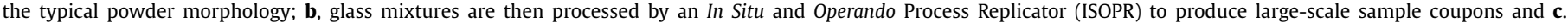
glass structures of Imperial College London crossover with University College London (ICL x UCL).

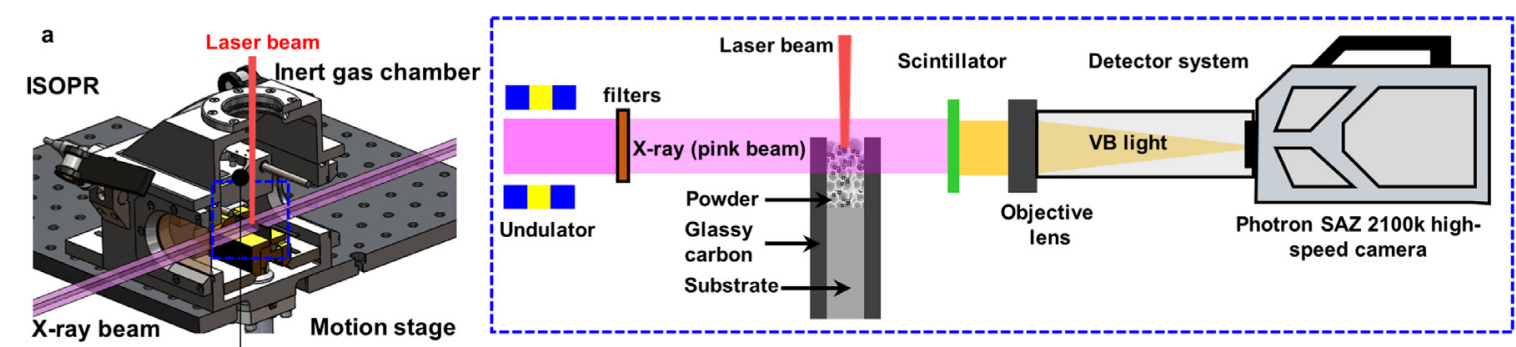

\section{Powder hopper}
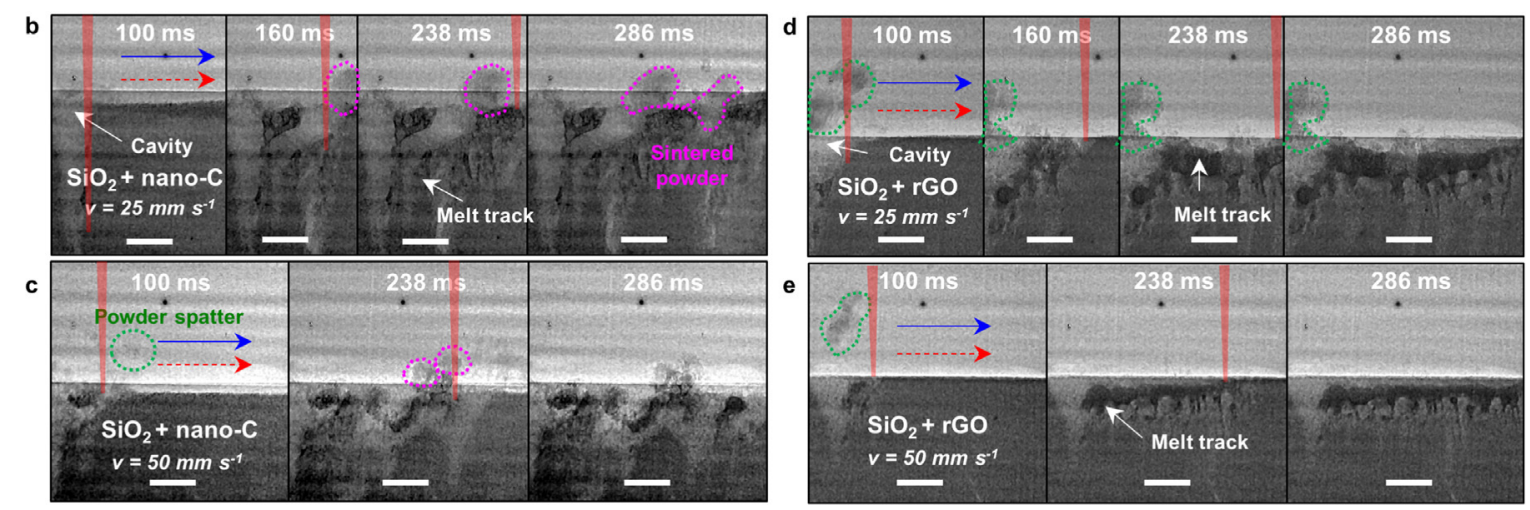

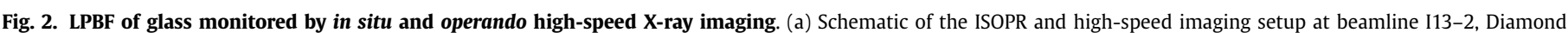

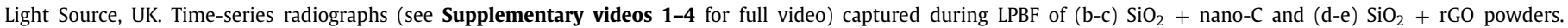

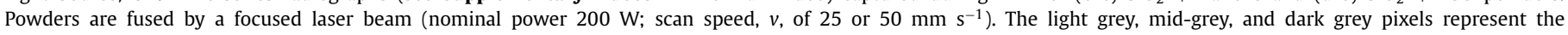

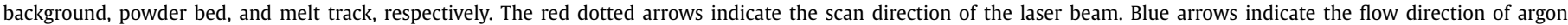
gas. Magenta and green highlights show the sintered powder and powder spatter, respectively. Scale bar $=1 \mathrm{~mm}$. 
i.e. the carbothermal reduction, liberating $\mathrm{CO}, \mathrm{CO}_{2}$, and $\mathrm{SiO}$ gases [51] but this process usually takes over several hours rather than over ms. Though the ISOPR's chamber operates at a positive pressure of $10 \mathrm{kPa}$, this may lower the vapour pressure and softening temperature of $\mathrm{SiO}_{2}$, accelerating the carbothermal reduction process. Thirdly, the decomposition of oxygen-functional groups in the $\mathrm{SiO}_{2}+$ nano-C or rGO powder mixtures into $\mathrm{H}_{2} \mathrm{O}, \mathrm{CO}$, and $\mathrm{CO}_{2}$, at elevated temperature $\left(150-195{ }^{\circ} \mathrm{C}\right)$ [52], see X-ray Photoelectron Spectroscopy (XPS) and Thermogravimetric analysis (TGA) results. Fourthly, the residual oxygen in the inert gas may also attribute to the reaction between carbon and oxygen at elevated temperature. Consequently, the combination of gas liberation with low temperature volatiles, i.e. plume generation, induces powder spatter during LPBF.

Once the scanning mirror reaches its maximum speed, only a small amount of powder spatter is observed, confirming our prior hypothesis regarding that the initial ejecta event is based on vaporisation of the metallic substrate. Though we observe a different kind of spatter where a large cluster of sintered powder with a large drag coefficient, expels upwards, and lands near the lasermatter interaction zone.

As the LPBF progresses, the glass track appears in the radiograph at $160 \mathrm{~ms}$ (as shown by the dark grey features in Fig. 2b). The glass features are slowly merging and growing into a glass track by the viscous flow mechanism $[18,22]$. Powder sintering occasionally occurs on top of the powder bed (highlighted by the purple dotted circle) because the laser beam remelts the powder spatter, forming a hump on the glass track surface (see $60-70 \mathrm{~ms}$ and $120-180 \mathrm{~ms}$ in Supplementary video $\mathbf{1}$ ).

The evolution mechanisms of the fused silica glass tracks are distinctively different from those revealed during LPBF of metal powders $[18,33,41]$. We reveal that the bubble formation inside the melt track during LPBF is strongly linked to the plume generation mechanisms described earlier. These bubbles can grow at the expense of others via coalescence and subsequently expand and collapse. Some of them are trapped inside the glass track because of the high viscosity of $\mathrm{SiO}_{2}$ which is ca. 1.6-2.7 Pa s [53] at its softening temperature range of $1500-1670{ }^{\circ} \mathrm{C}$. These trapped bubbles may shrink to a smaller size, becoming pores as the glass track vitrifies. Compared to LPBF of metal powders, a typical viscosity of the liquid metals is in the order of $10^{-3}$ Pa S [54], ca. 3 orders magnitude lower than that of $\mathrm{SiO}_{2}$. The liquid metal can migrate bubbles within the melt pool and towards the melt surface via Marangoni convection [33,41]. This allows bubbles to escape either via the keyhole/vapour depression or from the melt surface [41]. Our results confirm that a high viscosity melt dampens the convective flow and promotes pore formation during $\mathrm{LPBF}$ of $\mathrm{SiO}_{2}$, similar to that observed during LPBF of 13-93 bioactive glass [18]. We can summarise that the evolution mechanism of glass track undergoes a recurring sequence of events: (1) formation of a cavity, followed by (2) plume generation, (3) spatter formation, (4) melt track formation (with possible powder sintering), (5) bubble formation and collapse, and (6) bubble shrinkage as the glass track cools, see radiographs at 238 and $286 \mathrm{~ms}$.

Under this processing condition, a porous and irregular glass track is formed as a result of excessive heat input to the LPBF process. To confirm that, we lower the heat input by increasing $v$ from 25 to $50 \mathrm{~mm} \mathrm{~s}^{-1}$ (Fig. 2c and Supplementary video 2) which reduces the size of the cavity and the track depth. From Fig. 2c, the glass track appears much denser than that in Fig. $2 \mathbf{b}$ as it absorbs more of the incoming X-rays and hence appears darker in the radiographs. However, increasing $v$ in LPBF causes frequent powder spatter and sintered ejecta at the laser-matter interaction zone $(100 \mathrm{~ms})$, and hence more powder particles land on top of the powder bed. These experiments prove that the nano- $C$ additive increases the NIR absorbance of powder feedstock; however, the glass tracks $\left(\mathrm{SiO}_{2}+\right.$ nano- $\left.\mathrm{C}\right)$ produced under the conditions studied exhibit an irregular track shape and a large amount of porosity, suggesting that it is not an ideal NIR absorber for the LPBF process.

In the $\mathrm{SiO}_{2}+$ rGO study, (Fig. 2d and Supplementary video 3 ) we reveal similar phenomena as those described in Fig. $2 \mathbf{b}$ and $\mathbf{c}$, in terms of the track formation process. However, there are several unique observations with $\mathrm{LPBF}$ of $\mathrm{SiO}_{2}+\mathrm{rGO}$, suggesting that rGO performs significantly better than the nano- $C$ additive. The $\mathrm{SiO}_{2}+$ rGO glass tracks exhibit a continuous line shape, suggesting that the rGO provides a better laser absorption for the $\mathrm{SiO}_{2}$ glass mixture compared to that with nano- $C$ additive, i.e. further enhanced the laser absorbance of $\mathrm{SiO}_{2}$. During $\mathrm{LPBF}$ of $\mathrm{SiO}_{2}+\mathrm{rGO}$, significantly less spatter is produced. Moreover, the additive manufactured glass tracks have less porosity and warpage than those produced with $\mathrm{SiO}_{2}+$ nano-C (see frames at $286 \mathrm{~ms}$ in Fig. 2d,e, respectively).

Neither rGO nor nano- $\mathrm{C}$ is thermally stable, both additives may emit $\mathrm{CO}, \mathrm{CO}_{2}$, and $\mathrm{SiO}$ gas during LPBF even under an argon protective environment [51]. We hypothesise that nano- $\mathrm{C}$ is less stable than rGO at elevated temperature owing to its highly reactive surface and disordered structure [55]. The TGA results (Supplementary Figure 2) show that the $\mathrm{SiO}_{2}+$ nano-C powder mixture lost ca. 7 times more weight than that of the $\mathrm{SiO}_{2}+\mathrm{rGO}$ powder mixture at elevated temperature (up to $1600^{\circ} \mathrm{C}$ ). This suggests that there are less volatile substances on the $\mathrm{rGO}$ and indicates that LPBF of $\mathrm{SiO}_{2}+$ nano-C additive can liberate more gas bubbles than $\mathrm{SiO}_{2}+\mathrm{rGO}$.

Under the LPBF conditions, the melting temperature of the fused silica is high, the pressure in the melt track is in a few order magnitudes lower than the required pressure for $\mathrm{CO}_{2}$ to dissolve into the silica melt [56], and hence it exolves as a gas molecule. The migration of gas pores is slow within the viscous glass, trapping inside the $\mathrm{SiO}_{2}$ track. Moreover, the laser melting process may also trap some of the argon gas from the environment into the glass track. The side effect of the bubble collapse can also lead to spatter formation (see 96 - $104 \mathrm{~ms}$ in Supplementary video 3), reducing the amount of powder available for LPBF and resulting in a low-density region in the glass track, see the light grey colour in the middle of the $\mathrm{SiO}_{2}+$ nano- $\mathrm{C}$ tracks.

Comparing these observations with prior studies under overhang conditions (only with powder support) [18,33,41], all metallic tracks tend to extend towards the bottom of the powder bed rather than those observed here. Here, we demonstrate, for the first time, the possibility of producing a $5 \mathrm{~mm}$ long track of $\mathrm{SiO}_{2}+\mathrm{rGO}$ under overhang conditions which is unprecedented as existing LPBF machines require support structures to fabricate overhang features unless the powder bed is preheated at high temperature $[57,58]$.

Using the ISOPR we can explore the process parameter space with immediate feedback. Increasing $v$ further reduces the internal porosity, warpage, and melt depth of the AM track (Fig. 2e and Supplementary video 4). Our results demonstrate that rGO offers many benefits when processing $\mathrm{SiO}_{2}$, including increasing NIR absorption, provision of homogenous heating across the powder bed, and enhancing the thermal conductivity of the powder bed while decreasing the warpage and porosity. Fig. $2 \mathbf{d}$ and e show streak-like melt features near the bottom of the glass tracks of $\mathrm{SiO}_{2}+\mathrm{rGO}$, see green arrows at $286 \mathrm{~ms}$. These features are possibly formed when the scattered and attenuated laser beam starts to interact with the rGO, melting the fused silica matrix by the photothermal and radiation conduction mechanisms. These streaklike melt features stop growing once the attenuated beam energy is fully absorbed by the rGO.

We further investigate the effects of $v$ on the melting or vitrification process by performing systematic trail runs whilst imaging these processes with X-rays. We segmented the radiographs and assembled a time-integrated image (using methods depicted 


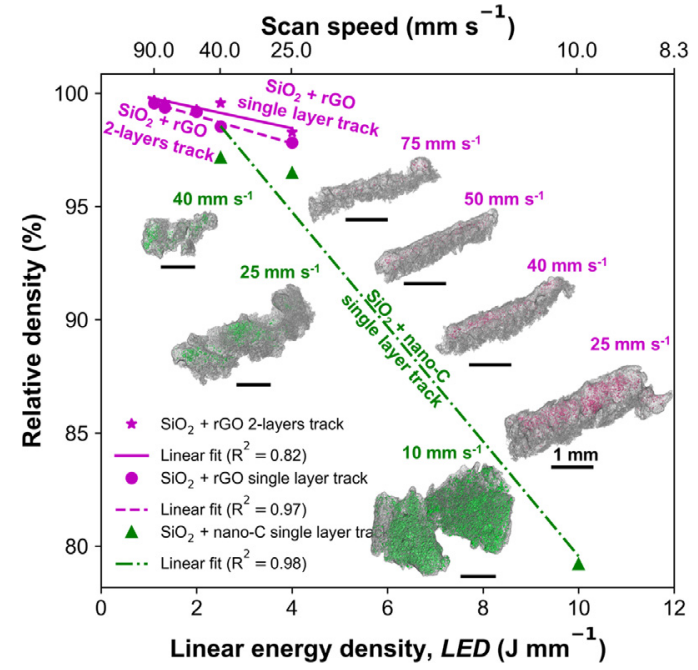

Fig. 3. Relative density (\%) plot of glass tracks produced by LPBF. The green and magenta colours indicate the results from $\mathrm{SiO}_{2}+$ nano- $\mathrm{C}$ and $\mathrm{SiO}_{2}+\mathrm{rGO}$, respectively. The linear energy density is calculated by dividing laser power and scan speeds. The three-dimensional rendered image volumes are generated from X-ray computed tomography scans and they are overlaid with their corresponding pore volume. Scale bar $=1 \mathrm{~mm}$.

in [33]) to aid the visualisation of the LPBF process over time. We combine these images to form a mechanism map as shown in Supplementary Figure 3. For the case of $\mathrm{SiO}_{2}+$ nano-C, we can see that a significant amount of powder spatter is shown under the conditions studied, the glass track becomes more discontinuous with increasing $v$ and no glass tracks are formed at $v>40 \mathrm{~mm} \mathrm{~s}^{-1}$, see selected SEM images in Supplementary Figure 4a-c. For the case of $\mathrm{SiO}_{2}+\mathrm{rGO}$, we successfully built continuous tracks across $v$ of $25-90 \mathrm{~mm} \mathrm{~s}^{-1}$, see selected SEM images in Supplementary Figure 4d-f and X-ray computed tomography (XCT) images of the glass tracks in Fig. 3.

We employed XCT to assess the relative density of the built tracks over a wide range of processing parameters (see Fig. 3). In general, the relative density of the glass tracks increases linearly with $v$ (or linear energy density, $L E D=P / v$ ). At fast $v$ (or the lower input $L E D$ ), this reduces vaporisation of low temperature volatiles within the powder mixtures (a.k.a. the reboil effect [59]) and minimises possible reaction between the additive and $\mathrm{SiO}_{2}$.

For the $\mathrm{SiO}_{2}+$ nano- $\mathrm{C}$, the relative density increases from $\mathrm{ca}$. $79.8 \%$ to $98.5 \%$ with increasing $\mathrm{v}$; however, the track length of $\mathrm{SiO}_{2}+$ nano-C is shorter than that produced with $\mathrm{SiO}_{2}+\mathrm{rGO}$. This is because the nano- $C$ exhibits a low laser absorbance, the powder mixture absorbs insufficient energy to undergo complete melting, and there is insufficient time for trapped gas to escape from the melt pool, forming pores in the glass track as the glass structure cools. For the $\mathrm{SiO}_{2}+\mathrm{rGO}$, the relative density also increases from $97.8 \%$ to $99.6 \%$ with increasing $v$. However, our results show that AM of $\mathrm{SiO}_{2}+\mathrm{rGO}$ has a better control of porosity over a wide range of $L E D$. Here, we confirm that both nano- $C$ and $\mathrm{rGO}$ additives can enhance the NIR absorbance of $\mathrm{SiO}_{2}$ and enable the melting and vitrification of $\mathrm{SiO}_{2}$ using a NIR laser system.

\subsection{Mechanistic insights into the laser absorption mechanism}

The SEM images (Supplementary Figure 5) examine the morphology of five different powder feedstocks: (1) spherical $\mathrm{SiO}_{2}$ powder particles (Supplementary Figure 5a); (2) large secondary powder formed by a cluster of primary nano-C particles (Supplementary Figure 5b); and (3) the flake-like graphene oxide (GO) Supplementary Figure 5c). (4) The $\mathrm{SiO}_{2}+$ nano-C powder mix- ture (Supplementary Figure 5d), exhibits smaller clusters of nanoC particles, some of which further break down into finer nanoparticles during mechanical mixing, and subsequently adhered to the $\mathrm{SiO}_{2}$ powder surface. For the $\mathrm{SiO}_{2}+$ rGO powder mixture, the size of the GO flakes (Supplementary Figure 5c) is expected to reduce after mechanical mixing and heat treatment, forming rGO particles (Supplementary Figure 5e). The as-received powder size distributions are available in Supplementary Figure 6 and Materials and Methods.

The X-ray Diffraction (XRD) patterns of the as-supplied $\mathrm{SiO}_{2}$ and two other powder mixtures (Supplementary Figure 7) exhibit a combination of a broad (amorphous $\mathrm{SiO}_{2}$ ) diffraction peak and some weak crystalline (quartz) diffraction peaks. The absence of nano- $C$ and rGO peaks in the XRD pattern is owing to their small mass fraction ( $<5 \mathrm{wt} . \%)$ in the powder mixture which is below the detection limit of the XRD system.

The diffuse reflectance or $F(R)$ measurements (Fig. 4a) are closely linked to the laser absorbance of the powder feedstocks [18]. The $F(R)$ measurements in the wavelength $(\lambda)$ range of 1030 - $1070 \mathrm{~nm}$ are of utmost interest, matching most commercial LPBF systems, see the red region of interest (ROI). Under normal operation, these systems are used primarily for processing some metallic systems due to their relatively high laser absorbance of $A=0.53-$ 0.81 [16], while other materials are difficult to process, including polymers $(A=0.07-0.52)$ [17], glass $(A \leq 0.03)$ [15,18], and ceramics $(A=0.15)$ [20]. As expected, the $F(R)$ of $\mathrm{SiO}_{2}$ as-supplied powder shows a negligible IR absorbance [60] in the ROI, confirming that neither the amorphous or quartz phases have active laser absorption mechanisms at $\lambda$ ranging from 900 to $1400 \mathrm{~nm}$. The $F(R)$ of powder mixtures of $\mathrm{SiO}_{2}+$ nano-C is ca. 0.3 , similar performance to that reported in prior work [40]. Moreover, the $\mathrm{SiO}_{2}+$ rGO mixture has a $F(R)$ of $c a .0 .9$ and hence a 20 -fold better in NIR absorption than that of $\mathrm{SiO}_{2}(F(R)<0.05)$ within the ROI.

We determine the optical bandgaps $\left(\boldsymbol{E}_{\boldsymbol{g}}\right)$ of nano-C and rGO using the tangent of Tauc plots, their $\boldsymbol{E}_{\boldsymbol{g}}$ is estimated as $0.656 \mathrm{eV}$ (Fig. 4b) and $0.553 \mathrm{eV}$ (Fig. 4c), respectively. Our results match well with the previously reported results in which the $\boldsymbol{E}_{\boldsymbol{g}}$ of amorphous carbon varies from 0.45 to $2.12 \mathrm{eV}$ [61] depending on the hydrogen content whereas the rGO has a variable $\boldsymbol{E}_{\boldsymbol{g}}$ from 0.02 to $2 \mathrm{eV}$ depending on the degree of reduction [62]. The incoming laser energy of $1.1-1.2 \mathrm{eV}$ (at $1030-1070 \mathrm{~nm}$ ) is greater than $\boldsymbol{E}_{\boldsymbol{g}}$ of nano-C and rGO, sufficient to enable the transit of electrons from the valence to the conduction band, i.e. $\pi-\pi^{*}$ transition, and then inducing a photothermal effect, this is followed by the radiation conduction and melting of $\mathrm{SiO}_{2}$ [18]. The low $E_{g}$ of $\mathrm{rGO}$ means that less photon energy is required for inducing the photothermal effect than that required by nano-C, however, this only partially explains why the laser absorbance of rGO is better than that of nano-C.

The ATR-FTIR spectra (Fig. 4d) show typical IR absorption responses from the $\mathrm{SiO}_{2}$ powder feedstock (see peak assignment information in Supplementary Table 2 and the full spectrum in Supplementary Figure 8). For the $\mathrm{SiO}_{2}+\mathrm{rGO}$ powder, Fig. 4d shows C-C stretching vibrations $\left(1080 \mathrm{~cm}^{-1}\right)$ [63], C-O stretching vibrations (1046-1087 $\mathrm{cm}^{-1}$ ) [64], and the C-O-C stretching vibration from the basal planes of the epoxy groups $\left(1220 \mathrm{~cm}^{-1}\right)$ [65]. Both powder mixtures exhibit weak and broad absorption peaks (1500$2000 \mathrm{~cm}^{-1}$ ) arising from the $\mathrm{C}=\mathrm{C}$ bond vibrations. These additional IR absorption peaks in the $\mathrm{SiO}_{2}+$ nano- $\mathrm{C}$ and $\mathrm{SiO}_{2}+\mathrm{rGO}$ powder mixtures indicate that the presence of carbon bonds play a crucial role in the NIR absorption mechanism (Fig. 4 b).

Therefore, we probe further the chemical structure of both additives and compare them with the $\mathrm{SiO}_{2}$ powders using Raman spectroscopy, see Fig. 4c and Supplementary Table 3 for individual peak information. The low spectral response of borosilicate 

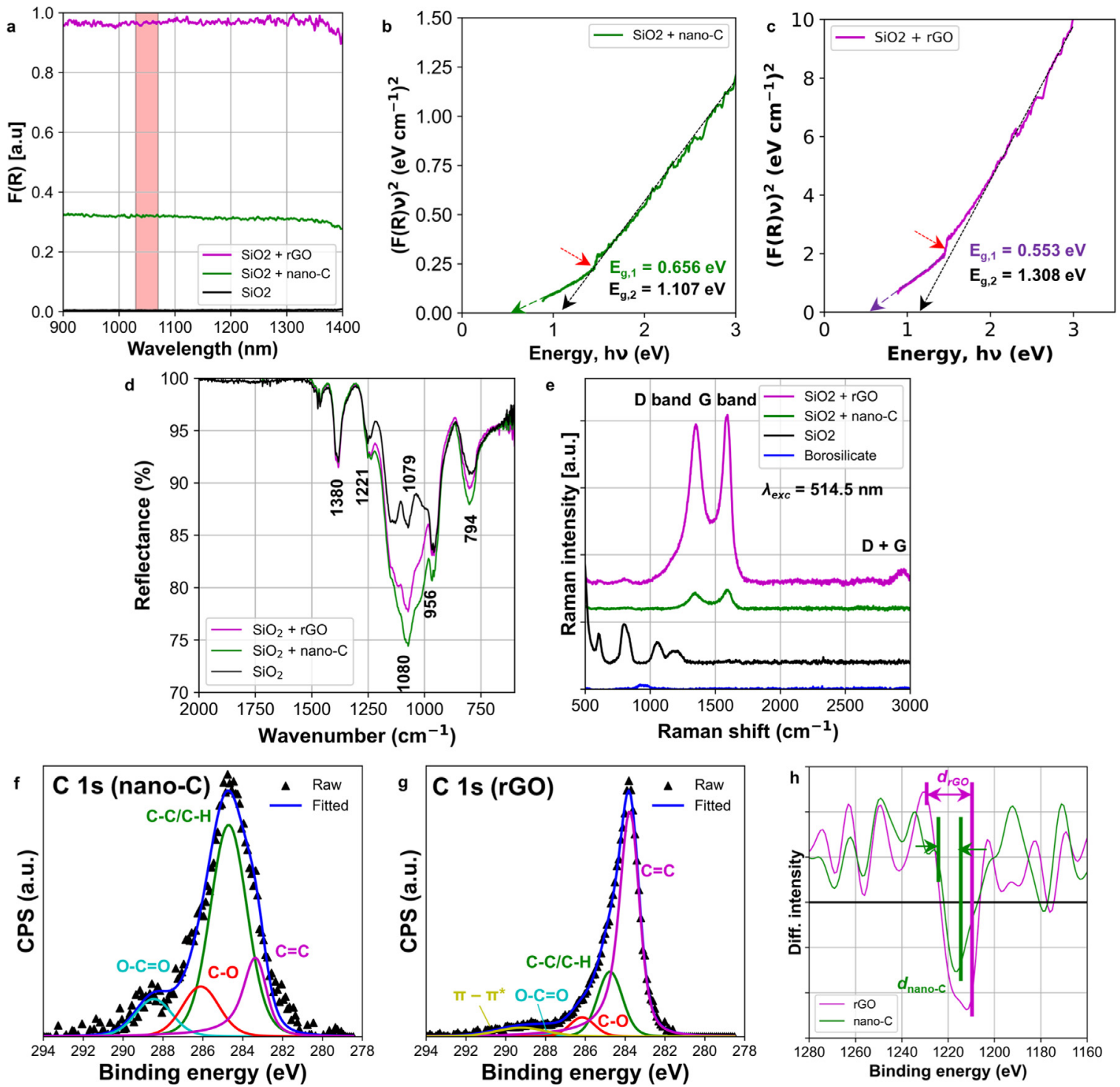

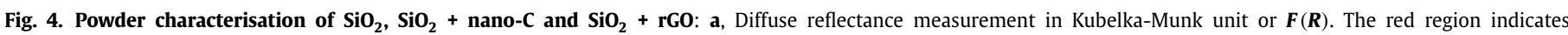

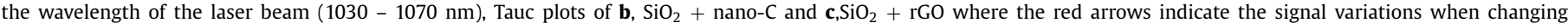

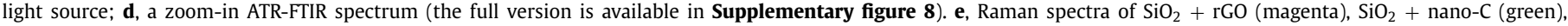

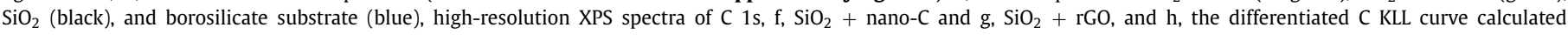

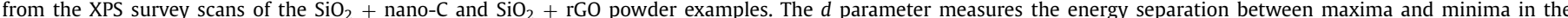

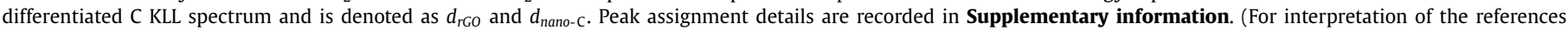
to color in this figure legend, the reader is referred to the web version of this article.)

glass makes it an excellent substrate material for the Raman spectroscopy. The $\mathrm{SiO}_{2}$ Raman spectrum only shows the presence of the amorphous $\mathrm{SiO}_{2}$ phase [66,67] and differs from the XRD results (Supplementary Figure 7) because the beam-powder interactive volume is significantly smaller in Raman spectroscopy than in XRD, and hence the XRD results are more statistically relevant. The $\mathrm{SiO}_{2}+$ nano-C Raman spectrum displays the $\mathrm{D}$ (defect) band $\left(1348 \mathrm{~cm}^{-1}\right)$ and the $\mathrm{G}$ (graphite) band $\left(1585 \mathrm{~cm}^{-1}\right)$ whereas the $\mathrm{SiO}_{2}+$ rGO Raman spectrum exhibits strong peak signals in the $\mathrm{D}$ band $\left(1350 \mathrm{~cm}^{-1}\right)$, the $G$ band $\left(1594 \mathrm{~cm}^{-1}\right)$, and weak signals of $D+G$ band [68] or S3 band - a second-order peak derived from the $D+G$ band [69] $\left(2951.7 \mathrm{~cm}^{-1}\right)$. Neither of the powder mixtures shows the $\mathrm{SiO}_{2}$ Raman peaks due to the small laser beam size, confirming that the excitation laser beam mainly interacts with the nano- $C$ and rGO additives. The D band indicates the disorders of the chemical structure, its signal strength depends on the presence of defects and relates to the stretching of the $s p^{2}$ orbital in the material structure whereas the $\mathrm{G}$ band arises from the Raman active response for the combination of $s p^{2}$ hybridised orbital (basal plane) and $s p^{3}$ orbital (e.g. the functional group near the edge) of the additives. The prominent feature of the $D+G$ band in the $\mathrm{SiO}_{2}+$ rGO powder mixture [70] is owing to the chemical and edge/point defects induced by the reduction process of GO. We also quantify the amount of disorder, the degree of oxidation, or the average size of the $s p^{2}$ ring clusters of the carbon structure, $\boldsymbol{L}_{\boldsymbol{D}}$, using an intensity ratio of $\mathrm{D}$ and $\mathrm{G}$ bands [71-73], i.e. $\frac{I_{D}}{I_{G}}$ [29], and $\boldsymbol{L}_{\boldsymbol{D}}(\boldsymbol{n m})=\frac{560}{\boldsymbol{E}_{\lambda}}\left(\frac{\boldsymbol{I}_{\boldsymbol{D}}}{\boldsymbol{I}_{\boldsymbol{G}}}\right)^{-1}$ [74] where $E_{\lambda}$ is the Raman excitation energy $(\mathrm{eV})$ and $\lambda$ of the laser beam is $514.5 \mathrm{~nm}$. The $I_{D} / I_{G}$ ratio of $\mathrm{SiO}_{2}+$ nano-C and $\mathrm{SiO}_{2}+\mathrm{rGO}$ is calculated as 0.85 and 0.94 (similar to the value calculated from prior work [75]), and hence the $\boldsymbol{L}_{\boldsymbol{D}}$ is estimated to be $19.3 \mathrm{~nm}$ and $17.5 \mathrm{~nm}$, respectively. Comparing these results with a high purity graphene domain of rGO with an $L_{D}$ of $8.96 \mathrm{~nm}$ [76], we can confirm that both additives are highly disordered. 
Table 1

XPS quantification analysis of the $\mathrm{C} 1 \mathrm{~s}$ scan in $\mathrm{SiO}_{2}+$ nano-C and $\mathrm{SiO}_{2}+\mathrm{rGO}$ powder mixtures.

\begin{tabular}{llll}
\hline Powder type & Bonds & Peak position $(\mathrm{eV})$ & Atomic concentration (at.\%) \\
\hline $\mathrm{SiO}_{2}+$ nano-C & $\mathrm{C}=\mathrm{C}$ & 283.3 & 17.5 \\
& $\mathrm{C}-\mathrm{C} / \mathrm{C}-\mathrm{H}$ & 284.7 & 58.4 \\
& $\mathrm{C}-\mathrm{O}$ & 286.1 & 13.8 \\
$\mathrm{SiO}_{2}+\mathrm{rGO}$ & $\mathrm{O}-\mathrm{C}=\mathrm{O}$ & 288.5 & 10.3 \\
& $\mathrm{C}=\mathrm{C}$ & 283.7 & 67.6 \\
& $\mathrm{C}-\mathrm{C} / \mathrm{C}-\mathrm{H}$ & 284.7 & 20.0 \\
& $\mathrm{C}-\mathrm{O}$ & 286.1 & 0.8 \\
& $\mathrm{O}-\mathrm{C}=\mathrm{O}$ & 288.4 & 6.0 \\
& $\pi-\pi^{*}$ & 289.9 & 5.6 \\
\hline
\end{tabular}

By probing the surfaces of both additives using XPS, the $\mathrm{O} / \mathrm{C}$ ratio of both carbon additives is estimated to be 0.28 (nano-C) and 0.09 (rGO), respectively (see details in (Supplementary Figure 9 and Supplementary Table 4). It is well documented that the smaller the $\mathrm{O} / \mathrm{C}$ ratio, the smaller the $\boldsymbol{E}_{\boldsymbol{g}}$, further supporting our findings from Fig. 4a-c. [62]

Our results also confirm that the carbon species are responsible for the enhanced NIR absorption mechanisms but further information is needed to explain the performance difference between the two additives. By comparing the C 1s spectra (Fig. $4 \mathbf{f}-$ g), both powders exhibit $\mathrm{C}=\mathrm{C}(\sim 283.7 \mathrm{eV}), \mathrm{C}-\mathrm{C} / \mathrm{C}-\mathrm{H}(\sim 284.7 \mathrm{eV})$, $\mathrm{O}-\mathrm{C}=\mathrm{O}(\sim 288.5 \mathrm{eV}), \mathrm{C}-\mathrm{O}(\sim 286.1 \mathrm{eV})$ species, the peak assignment matches well with the 01s and Si 2p spectra (Supplementary Figure 10a-d) and ATR-FTIR results (Fig. 4d). However, the deconvoluted $\mathrm{C} 1 \mathrm{~s}$ spectrum $\mathrm{SiO}_{2}+\mathrm{rGO}$ powder mixture shows a satellite peak at $289.9 \mathrm{eV}$ due to the $\pi-\pi^{*}$ shake-up processes arising from the aromatic rings in the rGO backbone which corroborates with the evidence shown in Fig. 4c-d. We quantify individual peak positions and calculate the atomic concentration (at.\%) of different carbon species in the $\mathrm{SiO}_{2}+$ nano-C and $\mathrm{SiO}_{2}+\mathrm{rGO}$ powder mixtures, see details in Materials and Methods and Table 1. We use the differentiated X-ray induced C KLL spectra (Fig. 4h) to estimate the $d$ parameter of nano-C $\left(d_{r G O}\right)$ and $\mathrm{rGO},\left(d_{r G O}\right)$, which are $10 \mathrm{eV}$ and $28 \mathrm{eV}$, indicating that the $\mathrm{rGO}$ is $s p^{2}$-like material and nano-C is $s p^{3}$-like material, respectively (see details in Supplementary information) [77]. The $d$ parameter values also support our calculated $L_{D}$ values because the $s p^{3}$ in nano-C causes a distortion to the honeycomb graphene lattice, and thus the $L_{D}$ of nano- $C$ is higher than that of $\mathrm{rGO}$ [78]. Fig. $\mathbf{4 g}$ and Table 1 show that the $\mathrm{C}=\mathrm{C}$ species in $\mathrm{rGO}$ is $\mathrm{ca} .4$ times higher than that in nano- $\mathrm{C}$ (Fig. 4f) whereas the $\mathrm{C}=\mathrm{O}$ and $\mathrm{O}-\mathrm{C}=\mathrm{O}$ in $\mathrm{rGO}$ are significantly lower than that of the nano- $C$ due to the restoration of the $s p^{2}$ graphitic domains. The $\pi-\pi^{*}$ transition (Fig. $4 \mathbf{g}$ ) from the $\mathrm{C}=\mathrm{C}$ and aromatic rings in addition to the $\pi$ conjugation between planes of rGO flakes seem to play a crucial role in the NIR absorption mechanism. It is well documented that the $s p^{2}$ domains of rGO exhibit non-linear optical properties [76], including Saturation Absorption (SA) in $s p^{2}$ carbon clusters and Two-Photon Absorption (TPA) and excited-state absorption (ESA) in small localised $s p^{2}$ carbon and $s p^{3}$ carbon matrix, respectively [78]. The delocalised electrons (or surface plasmons [79]) in the valence band from the $s p^{2}$ carbon configuration and $s p^{2}$ carbon cluster reduces the $\boldsymbol{E}_{\boldsymbol{g}}$, and hence the $\boldsymbol{E}_{\boldsymbol{g}}$ of rGO is lower than that of nano-C (Fig. $4 \mathbf{b}, \mathbf{c}$ ). Given that the nano-C has fewer delocalised electrons (Fig. 4f) compared to those of the rGO, there are fewer electrons taking part in the photothermal conversion mechanism, resulting in a porous glass structure (Fig. 2b-c). In contrast, the rGO consists of a high number of delocalised electrons from the aromatic rings (Fig. $4 \mathbf{g}$ ), this promotes the melting and vitrification of $\mathrm{SiO}_{2}$ during $\mathrm{LPBF}$, resulting in highly dense tracks ( $\geq 97.8 \%$ ) under the conditions studied (Fig. 2d,e).

\section{Conclusions}

In summary, we demonstrate the application of nano carbon (nano-C) and reduced graphene oxides ( $\mathrm{rGO}$ ) as NIR absorbers for laser powder bed fusion (LPBF). Our results provide mechanistic insights into the laser absorption, evolution mechanisms of glass track, and defects, e.g. spatter and bubbles, during LPBF of $\mathrm{SiO}_{2}$ with two types of carbon additives. In this study, the rGO exhibits a larger amount of $\mathrm{C}=\mathrm{C}$ bonds with small $s p^{2}$ graphitic domains and the $\pi$ conjugations between rGO additives combined with a low $\mathrm{O} / \mathrm{C}$ ratio, resulting in a smaller optical bandgap $(0.553 \mathrm{eV})$ than nano-C $(0.656 \mathrm{eV})$ for the photothermal effect and radiation conduction mechanism to take place. Our XCT analysis demonstrates that nano- $C$ additives can enable the production of tracks with a relative density of $>80 \%$, while tracks made by rGO achieve a relative density of $99.7 \%$. We show that rGO performs much better than nano-C as an NIR absorber with 3 times increase in NIR absorption, and it also reduces porosity and warpage in the LPBF tracks. Here, we demonstrate that the rGO offers a huge potential to improve the processability of low NIR absorbance materials and can be applied to other types of feedstock materials, e.g. wire, rods, sheets, etc., opening new possibilities for laser processing, beyond additive manufacturing. Our work takes us a step closer towards enabling the processing of different classes of materials using a single NIR laser system.

\section{Materials and methods}

\subsection{Materials synthesis}

As-supplied $\mathrm{SiO}_{2}$ powder (SS1206, Industrial Powder, USA) was selected due to its low NIR absorbance and two carbon additives were selected as a NIR enhancer to improve the processability of feedstock materials: (1) graphene oxide (GO) flake was prepared from natural graphite powder (Sigma Aldrich - Merck KGaA, Germany) using a custom-built reactor and a modified Marcano et al. [80] procedure described elsewhere [75], and (2) nano carbon (denoted as nano-C) (Sigma Aldrich - Merck KGaA, Germany). Both GO and nano- $\mathrm{C}$ powders were combined with $\mathrm{SiO}_{2}$ powder by vigorous mechanical mixing in methyl ethyl ketone (MEK) solvent (Acros Organics - ThermoFisherScientific, USA) using alumina milling media and TURBULA mixer for $10 \mathrm{~h}$. We collected the powder after the MEK was evaporated. After that, the $\mathrm{SiO}_{2}+$ nano-C powder was sieved through a $100 \mu \mathrm{m}$ mesh whereas the $\mathrm{SiO}_{2}+\mathrm{GO}$ powder was heat-treated at $950{ }^{\circ} \mathrm{C}$ in a tube furnace under $\mathrm{H}_{2} / \mathrm{Ar}$ atmosphere for $1.5 \mathrm{~h}$ and then sieved to produce a $\mathrm{SiO}_{2}$ powder covered with reduced graphene oxide ( $\mathrm{rGO}$ ). The resultant chemical composition of $\mathrm{SiO}_{2}+0.2$ wt.\% nano-C and $\mathrm{SiO}_{2}+0.2$ wt.\% rGO, see schematic in Fig. 1a.

\subsection{Powder characterisation}

The powder morphology was characterised using highresolution field emission gun scanning electron microscopy (LEO Gemini 1525 - FEG-SEM). Particle size analysis was performed using a Mastersizer 2000 laser diffraction particle size analyser (Malvern Panalytical Ltd., UK). The powder size distributions of $\mathrm{SiO}_{2}$, as supplied $\mathrm{C}$, and GO flakes are shown in (Supplementary Figure 5) in which their median particle size is $18 \mu \mathrm{m}, 70 \mathrm{~nm}$, and $30 \mu \mathrm{m}$ [75], respectively. The elemental composition of these powders was characterised by X-ray fluorescence (XRF) spectroscopy using a Panalytical Epsilon 3XL Benchtop XRF machine (Malvern Panalytical Ltd., UK) and data analysis was performed using Omnian software (Malvern Panalytical Ltd., UK). The crystal 
structure was examined by X-ray Diffraction (XRD) using a Panalytical X'Pert Pro MPD series automated spectrometer (Malvern Panalytical Ltd., UK) with a $C u_{K \alpha}$ radiation $(\lambda=1.541 \AA)$ at $40 \mathrm{kV}$ and $40 \mathrm{~mA}$, a $2 \theta$ scanning range (degrees) from $10^{\circ}$ to $100^{\circ}$ with a step size of $0.03^{\circ}$, and a count rate of $50 \mathrm{~s}$ per step. The phase identification of the XRD patterns and Rietveld refinement analysis were performed in Profex [81].

To understand the laser absorption behaviour, we measured the diffuse reflectance $(\boldsymbol{R})$ and the Kubelka-Munk measurement, $\boldsymbol{F}(\boldsymbol{R})$, of $\mathrm{SiO}_{2}, \mathrm{SiO}_{2}+$ nano-C, and $\mathrm{SiO}_{2}+\mathrm{rGO}$ powders using a UVVIS-NIR spectrophotometer using a single bounce diamond crystal and an integrating sphere attachment (UV-2600 and IRS-2600 plus, Shimadzu Corporation, Japan), see details in ref [18]. $\boldsymbol{F}(\boldsymbol{R})$ has been used to correlate the diffuse reflectance $(\boldsymbol{R})$, i.e. the IR absorbance of glass powders $[18,82]$.

Raman spectroscopy was performed on dry powder samples of $\mathrm{SiO}_{2}, \mathrm{SiO}_{2}+$ nano-C, and $\mathrm{SiO}_{2}+\mathrm{rGO}$ mounted on a borosilicate glass substrate using a Renishaw InVia Raman spectroscope (Renishaw plc, Wotton-under-Edge, UK). All samples were excited by an argon ion laser $\left(\lambda_{\text {exc }}=514.5 \mathrm{~nm}\right)$ via a $50 \mathrm{x}$ microscope objective $(\mathrm{NA}=0.4$, spot size $=c a .5 \mu \mathrm{m}$ ). The laser power used was optimised at $50 \%$ (ca. $1.4 \mathrm{~mW}$ ) to avoid saturating the chargedcoupled device. All spectra were collected with an exposure time of $30 \mathrm{~s}$ and 2 accumulations. We processed these spectra using the Renishaw WiRE 3.2 software and performed peak analysis using python (v.3.7) with NumPy [83], PeakUtils, Matplotlib, and SciPy libraries [84].

Attenuated total reflectance-Fourier transform infrared spectroscopy (ATR-FTIR) was used to identify functional groups of the powder mixtures. All spectra were collected at room temperature $\left(25^{\circ} \mathrm{C}\right)$ in the wavenumber range of $600-4000 \mathrm{~cm}^{-1}$ with a resolution of $2 \mathrm{~cm}^{-1}$ and an average of 16 scans using a Nicolet iS10 FT-IR Spectrometer (Thermo Fisher Scientific, USA).

The chemical states of $\mathrm{SiO}_{2}+$ nano- $\mathrm{C}$ and $\mathrm{SiO}_{2}+\mathrm{rGO}$ were examined by X-ray photoelectron spectroscopy (XPS) (Nexsa Surface Analysis System, Thermo Fisher Scientific Inc., USA). Both powder mixtures were characterised using a micro-focused monochromatic Al X-ray source $(72 \mathrm{~W})$ over an area of $c a .400 \times 200 \mu \mathrm{m}^{2}$. The XPS survey was conducted at pass energy of $200 \mathrm{eV}$ with a step size of $0.1 \mathrm{eV}$ and dwell time at $10 \mathrm{~ms}$. High-resolution scans were conducted at pass energy of $40 \mathrm{eV}$ with a step size of $0.1 \mathrm{eV}$ and a dwell time of $50 \mathrm{~ms}$. Charge neutralisation was applied to the sample using a combination of low energy electrons and $\mathrm{Ar}^{+}$ions at an argon partial pressure of $10^{-8}$ Torr in the $\mathrm{x}-\mathrm{y}$ scan mode, ion acceleration of $3 \mathrm{kV}$, and ion beam current density of $1 \mu \mathrm{Amm} \mathrm{mm}^{-2}$. Binding energies were referenced to Si $2 \mathrm{p}$ at $\sim 103.2 \mathrm{eV}$, with peak fitting undertaken using CasaXPS version 2.3.15 (Casa Software Ltd, UK).

To study the gas release during $\mathrm{LPBF}$, the $\mathrm{SiO}_{2}+$ nano- $\mathrm{C}$ and $\mathrm{SiO}_{2}+$ rGO powder mixture were loaded onto platinum pans under argon conditions and analysed by the Thermal Analysis instrument STA 449F1 (NETZSCH-Gerätebau GmbH, Germany) in a flowing argon atmosphere at a flow rate of $40-50 \mathrm{ml} \mathrm{min}^{-1}$. The weight of the samples was recorded following a heating profile: the furnace temperature was ramped to $1600{ }^{\circ} \mathrm{C}$ at a heating rate of $20^{\circ} \mathrm{C} \mathrm{min}^{-1}$ and then dwell for 15 mins. Lastly, the temperature was slowly ramped back to $20^{\circ} \mathrm{C}$.

\subsection{Real-time observation during laser powder bed fusion additive manufacturing}

To reveal the performance of $\mathrm{rGO}$ and nano- $\mathrm{C}$ on $\mathrm{SiO}_{2}$ during LPBF, we used a custom-built In Situ and Operando Process Replicator (ISOPR) to produce melt tracks whilst imaging how they were being built with synchrotron X-rays (Fig. 1b). The ISOPR has a miniature powder bed with a dimension of $46 \mathrm{~mm}$ (length) $\times 1.2 \mathrm{~mm}$ (wide) $\times 3 \mathrm{~mm}$ (depth) which is made out of two glassy carbon plates and a metal substrate (see details in the blue dotted rectangle) [33]. Although the ISOPR is equipped with an automated gravity feed hopper, powder particles were manually loaded onto the powder bed due to poor powder flowability. For each experiment, the environmental chamber was first evacuated to $10^{-3}$ mbar for $10 \mathrm{~s}$ and backfilled with argon gas at a constant flow rate of $41 \mathrm{~min}^{-1}$ to prevent oxidation. The ISOPR is equipped with a $200 \mathrm{~W} 1030$ - $1070 \mathrm{~nm} \mathrm{TEM}_{00}$ mode continuous wave laser with a spot size of $50 \mu \mathrm{m}\left(4 \sigma_{\mathrm{x}, \mathrm{y}}\right)$, see details in ref $[18,33,41]$. The laser beam is controlled by the BeamConstruct software (HALaser Systems, Germany). It was set to scan a $5 \mathrm{~mm}$ line at the powder bed with a laser power $(P)$ of $200 \mathrm{~W}$ and a range of scan speeds (v) from 10 to $90 \mathrm{~mm} \mathrm{~s}^{-1}$.

To visualise the LPBF process, we used pink beam imaging mode in the beamline I13-2 (Diamond Light Source, UK). The incoming X-ray beam from the undulator source was filtered by a $2.1 \mathrm{~mm} \mathrm{Al}$, a $1.34 \mathrm{~mm}$ graphite, and a Rhodium mirror, resulting in an energy range of $15-30 \mathrm{keV}$ (at an ID gap of $5 \mathrm{~mm}$ ). After the X-ray beam interacted with the powder bed, the attenuated X-ray converted into radiographs via a $300 \mu \mathrm{m} \mathrm{LuAg:} \mathrm{Ce} \mathrm{scintilla-}$ tor crystal coupled with a high-speed imaging camera (FASTCAM SAZ $2100 \mathrm{~K}$, Photron Ltd., USA) and a 4x objective lens. Each radiograph was recorded at $5 \mathrm{kHz}$ (and $0.2 \mathrm{~ms}$ ) with a field of view of $5.1 \times 5.1 \mathrm{~mm}$ and a $5 \mu \mathrm{m}$ pixel size.

The laser melting and image acquisition processes were synchronised using a digital signal level converter and position capture unit - Zebra (Quantum detector Ltd., UK). The camera was operated in a ring buffer mode that continuously recorded images into the on-board memory of the camera whilst waiting for an external trigger. Once the camera received the trigger signal, it saved ca. 3000 radiographs onto a local drive. The camera automatically performed a dark-field correction before image acquisition (Photron FASTCAM Viewer software, Photron Ltd., USA), therefore we only required to perform flat-field corrections by dividing the captured radiographs by an average of 100 flat-filed images. All images were denoised, segmented, and rendered as videos using a similar method depicted in ref. $[18,33,41]$.

\subsection{Post-build characterisation using X-ray computed tomography}

After the in situ radiography experiments, all built tracks were examined by a laboratory X-ray computed tomography (XCT) system (Nikon XTH 225 X-ray microfocus system, Nikon, Japan), using $50 \mathrm{kV}$ and $130 \mu \mathrm{A}$ with an exposure time of $500 \mathrm{~ms}$. Each scan acquired a total of 3176 projections All XCT scans were reconstructed into a 3D image volume with a voxel size of $2.7 \times 2.7 \times 2.7 \mu \mathrm{m}^{3}$ using built-in beam hardening correction and filtered back projection algorithms in CT Pro3D (Nikon, Japan), see ref [18]. The reconstructed image volumes were post-processed and quantified by Avizo 7.0 (Thermo Fisher Scientific, USA). We first applied a 3D median filter with a kernel size of $3 \times 3 \times 3$ for 2 iterations for noise reduction. After that, the glass structure was segmented from the filtered image using the Otsu threshold [85], resulting in a threshold image volume. Next, the volume of the glass structure (Volume (Vat $_{\text {) }}$ was calculated by applying connect component analysis [86] to the threshold image. We applied a Boolean negation operator to the threshold images and obtain the image volume only containing pores. Similar to the Volume mat quantification, the total volume of pores (Volume $_{\text {pore }}$ ) was quantified using connected component analysis, only accounting for objects with at least 5 voxels. A detailed analysis procedure is depicted in ref [87] and the relative density is calculated by Relative density = $\frac{\text { Volume }_{\text {pore }}}{\left(\text { Volume }_{\text {mat }}+\text { Volume }_{\text {pore }}\right)} \boldsymbol{x} 100 \%$. 


\section{Data availability}

Representative samples of the research data are given in the figures (and supplementary data - DOI if available). Other datasets generated and/or analysed during this study are not publicly available due to their large size but are available from the corresponding author on reasonable request.

\section{Author contributions}

CLAL, IE, PDL, and ES conceived the project. IE led the powder design, powder processing, performed SEM on powders and tracks, synchrotron experiments, heat-treatment, and hardness tests. CLAL led the LPBF process optimization and synchrotron experiments, performed XRD, XRF, TGA, Raman Spectroscopy, FTIR, ATR, and XCT analysis and results interpretation. SM and CLAL setup the synchrotron beamline and high-speed imaging setup. MI and CLAL analyzed and interpreted the XPS data. MI contributed to the investigation. CLAL and IE led the paper writing, with all authors contributing.

\section{Declaration of Competing Interest}

The authors declare that the corresponding authors have filed a patent (patent application number: GB2016624.5) based on this work.

\section{Acknowledgments}

This research was supported under MAPP: EPSRC Future Manufacturing Hub in Manufacture using Advanced Powder Processes (EP/P006566/1), a Royal Academy of Engineering Chair in Emerging Technology (CiET1819/10), EPSRC Impact Acceleration Account (EP/R511638/1), and the graphene synthesis was performed in a reactor funded by EP/K01658X/1. Laboratory space and facilities were provided by the Research Complex at Harwell. The authors thank Diamond Light Source for providing the beamtime (proposal number: MT19354) and staff at I13 beamline for technical assistance. We would like to thank Dr. Gavin Stenning for providing instrument time on the XRF and XRD instruments in the Materials Characterisation Laboratory at the ISIS Neutron and Muon Source. Special thanks to Dr. Sara Mosca for her assistance on the Raman spectroscopy experiments and Philip Holloway (Photron Ltd.) for providing the high-speed camera (FASTCAM SAZ 2100K) to perform this experiment. The XPS data collection was performed at the EPSRC National Facility for XPS ("HarwellXPS"), operated by Cardiff University and UCL, under Contract No. PR16195.

\section{Supplementary materials}

Supplementary material associated with this article can be found, in the online version, at doi:10.1016/j.apmt.2021.101009.

\section{References}

[1] S.A.M. Tofail, E.P. Koumoulos, A. Bandyopadhyay, S. Bose, L. O'Donoghue, C. Charitidis, Additive manufacturing: scientific and technological challenges, market uptake and opportunities, Mater. Today 21 (2018) 22-37.

[2] T.M. Pollock, Alloy design for aircraft engines, Nat. Mater. 15 (2016) 809-815.

[3] S.Y. Chin, Y.C. Poh, A.-.C. Kohler, J.T. Compton, L.L. Hsu, K.M. Lau, S. Kim, B.W. Lee, F.Y. Lee, S.K. Sia, Additive manufacturing of hydrogel-based materials for next-generation implantable medical devices, Sci. Robot. 2 (2017) eaah6451.

[4] J.R. Jones, Reprint of: Review of Bioactive Glass: From Hench to Hybrids, Acta. Biomaterialia. 23 (Suppl) (2015) S53-S82 PMID: 26235346, doi:10.1016/j. actbio.2015.07.019.

[5] J.H. Martin, B.D. Yahata, J.M. Hundley, J.A. Mayer, T.A. Schaedler, T.M. Pollock, 3D printing of high-strength aluminium alloys, Nature 549 (2017) 365-369.

[6] B. Zhang, K. Kowsari, A. Serjouei, M.L. Dunn, Q. Ge, Reprocessable thermosets for sustainable three-dimensional printing, Nat. Commun. 9 (2018) 1831.
[7] Z.C. Eckel, C. Zhou, J.H. Martin, A.J. Jacobsen, W.B. Carter, T.A. Schaedler, Additive manufacturing of polymer-derived ceramics, Science 351 (2016) 58-62 $(80-$.

[8] F. Kotz, K. Arnold, W. Bauer, D. Schild, N. Keller, K. Sachsenheimer, T.M. Nargang, C. Richter, D. Helmer, B.E. Rapp, Three-dimensional printing of transparent fused silica glass, Nature 544 (2017) 337-339.

[9] R.L. Truby, J.A. Lewis, Printing soft matter in three dimensions, Nature 540 (2016) 371-378.

[10] E. MacDonald, R. Wicker, 3D printing for increasing component functionality, Science 353 (2016) aaf2093 (80-.).

[11] H. Lee, C.H.J. Lim, M.J. Low, N. Tham, V.M. Murukeshan, Y.-.J. Kim, Lasers in additive manufacturing: A review, Int. J. Precis. Eng. Manuf. Technol. 4 (2017) 307-322.

[12] R.D. Turner, J.R. Wingham, T.E. Paterson, J. Shepherd, C. Majewski, Use of silver-based additives for the development of antibacterial functionality in Laser Sintered polyamide 12 parts, Sci. Rep. 10 (2020) 1-11.

[13] M. Fateri, A. Gebhardt, S. Thuemmler, L. Thurn, Phys. Procedia, in: Experimental investigation on Selective Laser Melting of glass, 56, Elsevier, 2014, pp. 357-364.

[14] M. Fateri, A. Gebhardt, A. Selective Laser Melting of Soda-Lime Glass Powder, Int. J. Appl. Ceram. Technol. 12 (2015) 53-61.

[15] K.C. Datsiou, E. Saleh, F. Spirrett, R. Goodridge, I. Ashcroft, D. Eustice, Additive manufacturing of glass with laser powder bed fusion, J. Am. Ceram. Soc. 102 (2019) 4410-4414.

[16] C.D. Boley, S.C. Mitchell, A.M. Rubenchik, S.S.Q. Wu, Metal powder absorptivity: modeling and experiment, Appl. Opt. 55 (2016) 6496.

[17] S.P. Garaba, H.M. Dierssen, An airborne remote sensing case study of synthetic hydrocarbon detection using short wave infrared absorption features identified from marine-harvested macro- and microplastics, Remote Sens. Environ. 205 (2018) 224-235.

[18] C.L.A. Leung, S. Marussi, M. Towrie, J. del Val Garcia, R.C. Atwood, A.J. Bodey, J.R. Jones, P.J. Withers, P.D. Lee, Laser-matter interactions in additive manufacturing of stainless steel SS316L and 13-93 bioactive glass revealed by in situ X-ray imaging, Addit. Manuf. 24 (2018) 647-657.

[19] A.V. Lisitsyn, L.A. Dombrovsky, V.Y. Mendeleyev, A.V. Grigorenko, M.S. Vlaskin, A.Z. Zhuk, Near-infrared optical properties of a porous alumina ceramics produced by hydrothermal oxidation of aluminum, Infrared Phys. Technol. 77 (2016) 162-170.

[20] E. Juste, F. Petit, V. Lardot, F. Cambier, Shaping of ceramic parts by selective laser melting of powder bed, J. Mater. Res. 29 (2014) 2086-2094.

[21] J. Luo, H. Pan, E.C. Kinzel, Additive Manufacturing of Glass, J. Manuf. Sci. E. 136 (6) (2014) 061024.

[22] C.E. Protasov, R.S. Khmyrov, S.N. Grigoriev, A.V. Gusarov, Selective laser melting of fused silica: Interdependent heat transfer and powder consolidation, Int. J. Heat Mass Transf. 104 (2017) 665-674.

[23] S.A. Khairallah, A.A. Martin, J.R.I. Lee, G. Guss, N.P. Calta, J.A. Hammons, M.H. Nielsen, K. Chaput, E. Schwalbach, M.N. Shah, M.G. Chapman, T.M. Willey, A.M. Rubenchik, A.T. Anderson, Y.M. Wang, M.J. Matthews, W.E. King, Controlling interdependent meso-nanosecond dynamics and defect generation in metal 3D printing, Science 368 (2020) 660-665 (80-.)

[24] B.J. Simonds, J.W. Sowards, J. Hadler, E. Pfeif, B. Wilthan, J. Tanner, C. Harris, P.A. Williams, J. Lehman, Procedia CIRP, in: Dynamic and absolute measurements of laser coupling efficiency during laser spot welds, Elsevier B.V., 2018, pp. 632-635.

[25] J. Trapp, A.M. Rubenchik, G. Guss, M.J. Matthews, In situ absorptivity measurements of metallic powders during laser powder-bed fusion additive manufacturing, Appl. Mater. Today 9 (2017) 341-349.

[26] K. Shahzad, J. Deckers, Z. Zhang, J.P. Kruth, J. Vleugels, Additive manufacturing of zirconia parts by indirect selective laser sintering, J. Eur. Ceram. Soc. 34 (2014) 81-89.

[27] T.B. Sercombe, G.B. Schaffer, Rapid Manufacturing of Aluminum Components, Science 301 (2003) 1225-1227 (80-.)

[28] C.Y. Wang, P.J. Bates, M. Aghamirian, et al., Quantitative Morphological Analysis of Carbon Black in Polymers used in Laser Transmission Welding, Weld World 51 (2007) 85-90.

[29] J. Bin Wu, M.L. Lin, X. Cong, H.N. Liu, P.H. Tan, Raman spectroscopy of graphene-based materials and its applications in related devices, Chem. Soc. Rev. 47 (2018) 1822-1873.

[30] M. Chen, X. Li, G. Ji, Y. Wu, Z. Chen, W. Baekelant, K. Vanmeensel, H. Wang, Novel composite powders with uniform TiB2 nano-particle distribution for 3D printing, J.P. Kruth, Appl. Sci. 7 (2017) 250.

[31] X.P. Li, G. Ji, Z. Chen, A. Addad, Y. Wu, H.W. Wang, J. Vleugels, J. Van Humbeeck, J.P. Kruth, Selective laser melting of nano-TiB2decorated AlSi10Mg alloy with high fracture strength and ductility, Acta Mater. 129 (2017) 183-193.

[32] M. Aden, V. Mamuschkin, A. Olowinsky, Influence of carbon black and indium tin oxide absorber particles on laser transmission welding, Opt. Laser Technol. 69 (2015) 87-91.

[33] C.L.A. Leung, S. Marussi, R.C... Atwood, M. Towrie, P.J... Withers, P.D. Lee, In situ X-ray imaging of defect and molten pool dynamics in laser additive manufacturing, Nat. Commun. 9 (2018) 1355.

[34] F. Klocke, A. McClung, C. Ader, Direct laser sintering of borosilicate glass, Proc. Solid Free. Fabr. Symp. (2004) 214-219, doi:10.26153/TSW/6986.

[35] S. Yuan, Y. Zheng, C.K. Chua, Q. Yan, K. Zhou, Electrical and thermal conductivities of MWCNT/polymer composites fabricated by selective laser sintering., Compos. Part A Appl. Sci. Manuf. 105 (2018) 203-213. 
[36] M. Dadkhah, A. Saboori, P. Fino, An overview of the recent developments in metal matrix nanocomposites reinforced by graphene, Materials 12 (2019) 2823.

[37] P.Sehrawat Abid, S.S. Islam, P. Mishra, S. Ahmad, Reduced graphene oxide (rGO) based wideband optical sensor and the role of Temperature, Sci. Rep. 8 (2018) 3537.

[38] S.M. Mousavi, F.W. Low, S.A. Hashemi, N.A. Samsudin, M. Shakeri, Y. Yusoff, M. Rahsepar, C.W. Lai, A. Babapoor, S. Soroshnia, S.M. Goh, S.K. Tiong, N. Amin, Development of hydrophobic reduced graphene oxide as a new efficient approach for photochemotherapy, RSC Adv. 10 (2020) 12851-12863.

[39] C. Kavitha, K. Bramhaiah, N.S. John, S. Aggarwal, Improved surface-enhanced Raman and catalytic activities of reduced graphene oxide-osmium hybrid nano thin films, R. Soc. Open Sci. 4 (2017).

[40] S. Chang, L. Li, L. Lu, J. Fuh, Selective Laser Sintering of Porous Silica Enabled by Carbon Additive, Materials 10 (2017) 1313.

[41] C.L.A. Leung, S. Marussi, M. Towrie, R.C. Atwood, P.J. Withers, P.D. Lee, The effect of powder oxidation on defect formation in laser additive manufacturing, Acta Mater 166 (2019) 294-305.

[42] S. Hocine, H. Van Swygenhoven, S. Van Petegem, C.S.T. Chang, T. Maimaitiyili, G. Tinti, D. Ferreira Sanchez, D. Grolimund, N. Casati, Operando X-ray diffraction during laser 3D printing, Mater. Today 34 (2019) 30-40.

[43] Y. Chen, S.J. Clark, C.L.A. Leung, L. Sinclair, S. Marussi, M.P. Olbinado, E. Boller, A. Rack, I. Todd, P.D. Lee, In-situ Synchrotron imaging of keyhole mode multi-layer laser powder bed fusion additive manufacturing, Appl. Mater. Today 20 (2020) 100650.

[44] Grady, M. M.; Wright, I., Types of Extraterrestrial Material Available for Study, Meteorites and the Early Solar System II, University of Arizona Press, Tucson, 943 pp., p.3-18

[45] C.E. Kehayias, S. MacNaughton, S. Sonkusale, C. Staii, Kelvin probe microscopy and electronic transport measurements in reduced graphene oxide chemical sensors, Nanotechnology 24 (2013) 245502.

[46] G. Yi, B. Xing, H. Zeng, X. Wang, C. Zhang, J. Cao, L. Chen, One-Step Synthesis of Hierarchical Micro-Mesoporous SiO2/Reduced Graphene Oxide Nanocomposites for Adsorption of Aqueous Cr(VI), J. Nanomater 2017 (2017).

[47] R.S. Khmyrov, C.E. Protasov, S.N. Grigoriev, A.V. Gusarov, Crack-free selective laser melting of silica glass: single beads and monolayers on the substrate of the same material, Int. J. Adv. Manuf. Technol. 85 (2016) 1461-1469.

[48] S. Klein, S. Simske, C. Parraman, P. Walters, D. Huson, S. Hoskins, 3D Printing Transparent Glass, NIP \& Digital Fabrication Conference (2), (2012) 336-337.

[49] M. Grabda, S. Oleszek-Kudlak, E. Shibata, T. Nakamura, Vaporization of zinc during thermal treatment of $\mathrm{ZnO}$ with tetrabromobisphenol A (TBBPA), J. Hazard. Mater. 187 (2011) 473-479.

[50] L. Brewer, Thermodynamic Properties of the Oxides and their Vaporization Processes, Chem. Rev. 52 (1953) 1-75, doi:10.1021/cr60161a001.

[51] S. Somiya, Handbook of Advanced Ceramics: Materials, Applications, Processing, and Properties: Second Edition, Elsevier Inc., 2013.

[52] S. Abdolhosseinzadeh, H. Asgharzadeh, H.S. Kim, Fast and fully-scalable synthesis of reduced graphene oxide, Sci. Rep. 5 (2015) 1-7.

[53] G. Urbain, Y. Bottinga, P. Richet, Viscosity of liquid silica, silicates and alumino-silicates, Geochim. Cosmochim. Acta 46 (1982) 1061-1072.

[54] J.J. Valencia, P.N. Quested, Thermophysical properties, ASM Handb. Cast. 15 (2008) 468-481.

[55] E. Illeková, K. Csomorová, Kinetics of oxidation in various forms of carbon, J. Therm. Anal. Calorim. (2005) 103-108 Springer.

[56] N. Solomatova, R. Caracas, R. Cohen, Carbon Speciation and Solubility in Silicate Melts in Earth's Interior, in: Geophysical Monograph, 249, American Geophysical Union (AGU), 2020, pp. 179-194.

[57] P. Vora, R. Martinez, N. Hopkinson, I. Todd, K. Mumtaz, Customised Alloy Blends for In-Situ Al339 Alloy Formation Using Anchorless Selective Laser Melting, Tech. 5 (2017) 24.

[58] K. Cooper, P. Steele, B. Cheng, K. Chou, Contact-free support structures for part overhangs in powder-bed metal additive manufacturing, Inventions 3 (1) (2018) 2.

[59] J. Luo, L.J. Gilbert, D.C. Peters, D.A. Bristow, R.G. Landers, J.T. Goldstein, A.M. Urbas, E.C. Kinzel, Bubble formation in additive manufacturing of glass, in: J.N. Vizgaitis, B.F. Andresen, P.L. Marasco, J.S. Sanghera, M.P. Snyder (Eds.), Advanced Optics for Defense Applications: UV through LWIR, SPIE, 2016, p. 98220D.

[60] L.V. Rodríguez-de Marcos, J.I. Larruquert, J.A. Méndez, J.A. Aznárez, Self-consistent optical constants of SiO_2 and Ta_2O_5 films, Opt. Mater. Express 6 (2016) 3622.

[61] D.B. Bogy, K.M. Krishnan, D.K. Veirs, M.D. Rubin, C.B. Hopper, B. Bhushan, Chemical structure and physical properties of diamond-like amorphous carbon films prepared by magnetron sputtering, J. Mater. Res. 5 (1990) 2543-2554.

[62] Y. Shen, S. Yang, P. Zhou, Q. Sun, P. Wang, L. Wan, J. Li, L. Chen, X. Wang, S. Ding, D.W. Zhang, Evolution of the band-gap and optical properties of graphene oxide with controllable reduction level, Carbon N. Y. 62 (2013) 157-164.

[63] V.R.S.S. Mokkapati, S. Pandit, J. Kim, A. Martensson, M. Lovmar, F. Westerlund, I. Mijakovic, Bacterial response to graphene oxide and reduced graphene oxide integrated in agar plates, R. Soc. Open Sci. 5 (11) (2018).
[64] M. Ates, E. Özten, The comparison of capacitor behaviors of polymethylcarbazole and polymethylcarbazole/graphene, J. Alloys Compd. 714 (2017) $433-442$.

[65] G. Xu, J. Malmstrom, N. Edmonds, N. Broderick, J. Travas-Sejdic, J. Jin, Investigation of the Reduction of Graphene Oxide by Lithium Triethylborohydride, J. Nanomater. 2016 (4021059) (2016).

[66] M. Chligui, G. Guimbretière, A. Canizarès, G. Matzen, Y. Vaills, P. Simon, New features in the Raman spectrum of Silica: Key-points in the improvement on structure knowledge, Phys. Rev. B (2010) 1-5.

[67] R.K. Biswas, P. Khan, S. Mukherjee, A.K. Mukhopadhyay, J. Ghosh, K. Muraleedharan, Study of short range structure of amorphous Silica from PDF using Ag radiation in laboratory XRD system, J. Non. Cryst. Solids 488 (2018) 1-9.

[68] S. Claramunt, A. Varea, D. López-Díaz, M.M. Velázquez, A. Cornet, A. Cirera, The importance of interbands on the interpretation of the raman spectrum of graphene oxide, J. Phys. Chem. C 119 (2015) 10123-10129.

[69] I.K. Moon, J. Lee, R.S. Ruoff, H. Lee, Reduced graphene oxide by chemical graphitization, Nat. Commun. 1 (2010) 1-6.

[70] M.J. Fernández-Merino, S. Villar-Rodil, J.I. Paredes, P. Solís-Fernández, L. Guardia, R. García, A. Martínez-Alonso, J.M.D. Tascón, Identifying efficient natural bioreductants for the preparation of graphene and graphene-metal nanoparticle hybrids with enhanced catalytic activity from graphite oxide, Carbon N. Y. 63 (2013) 30-44

[71] D. Ickecan, R. Zan, S. Nezir, Eco-Friendly Synthesis and Characterization of Reduced Graphene Oxide, J. Phys. Conf. Ser. 902 (012027) (2017)

[72] R.T. Ngaloy, A.M. Fontanilla, M.S.R. Soriano, C.S. Pascua, Y. Matsushita, I.J.A. Agulo, Highly Efficient Photocatalysis by Zinc Oxide-Reduced Graphene Oxide (ZnO-rGO) Composite Synthesized via One-Pot Room-Temperature Chemical Deposition Method, J. Nanotechnol. 2019 (1895043) (2019).

[73] V. Strong, S. Dubin, M.F. El-Kady, A. Lech, Y. Wang, B.H. Weiller, R.B. Kaner, Patterning and electronic tuning of laser scribed graphene for flexible all-carbon devices, ACS Nano 6 (2012) 1395-1403.

[74] B. Anand, A. Kaniyoor, S.S.S. Sai, R. Philip, S. Ramaprabhu, Enhanced optical limiting in functionalized hydrogen exfoliated graphene and its metal hybrids, J. Mater. Chem. C 1 (2013) 2773-2780.

[75] O.T. Picot, V.G. Rocha, C. Ferraro, N. Ni, E. D’Elia, S. Meille, J. Chevalier, T. Saunders, T. Peijs, M.J. Reece, E. Saiz, Using graphene networks to build bioinspired self-monitoring ceramics, Nat. Commun. 8 (14425) (2017).

[76] T.C. Sabari Girisun, M. Saravanan, V.R. Soma, Wavelength-Dependent Nonlinear Optical Absorption and Broadband Optical Limiting in Au-Fe203-rGO Nanocomposites, ACS Appl. Nano Mater 1 (2018) 6337-6348.

[77] A.J. Barlow, S. Popescu, K. Artyushkova, O. Scott, N. Sano, J. Hedley, P.J. Cumpson, Chemically specific identification of carbon in XPS imaging using Multivariate Auger Feature Imaging (MAFI), Carbon N. Y. 107 (2016) 190-197.

[78] S. Wang, Y. Dong, C. He, Y. Gao, N. Jia, Z. Chen, W. Song, The role of sp2/sp3 hybrid carbon regulation in the nonlinear optical properties of graphene oxide materials, RSC Adv. 7 (2017) 53643-53652.

[79] G.G. Jernigan, J.A. Nolde, N.A. Mahadik, E.R. Cleveland, J.E. Boercker, M.B. Katz, J.T. Robinson, E.H. Aifer, Physical properties of nanometer graphene oxide films partially and fully reduced by annealing in ultra-high vacuum, J. Appl. Phys. 122 (2017) 075301

[80] D.C. Marcano, D.V. Kosynkin, J.M. Berlin, A. Sinitskii, Z. Sun, A. Slesarev, L.B. Alemany, W. Lu, J.M. Tour, Improved synthesis of graphene oxide, ACS Nano 4 (2010) 4806-4814.

[81] N. Doebelin, R. Kleeberg, A graphical user interface for the Rietveld refinement program BGMN, J. Appl. Crystallogr. 48 (2015) 1573-1580.

[82] E. Ghadiri, S.M. Zakeeruddin, A. Hagfeldt, M. Grätzel, J.E. Moser, Ultrafast charge separation dynamics in opaque, operational dye-sensitized solar cells revealed by femtosecond diffuse reflectance spectroscopy, Sci. Rep. 6 (2016) 24465.

[83] S. Van Der Walt, S.C. Colbert, G. Varoquaux, The NumPy array: A structure for efficient numerical computation, Comput. Sci. Eng. 13 (2011) 22-30.

[84] P. Virtanen, R. Gommers, T.E. Oliphant, M. Haberland, T. Reddy, D. Cournapeau, E. Burovski, P. Peterson, W. Weckesser, J. Bright, S.J. van der Walt, M. Brett, J. Wilson, K.J. Millman, N. Mayorov, A.R.J. Nelson, E. Jones, R. Kern, E. Larson, C.J. Carey, I. Polat, Y. Feng, E.W. Moore, J. VanderPlas, D. Laxalde, J. Perktold, R. Cimrman, I. Henriksen, E.A. Quintero, C.R. Harris, A.M. Archibald, A.H. Ribeiro, F. Pedregosa, P. van Mulbregt, SciPy 1.0 Contributors, SciPy 1.0: fundamental algorithms for scientific computing in Python, Nat. Methods 17 (2020) 261-272.

[85] N. Otsu, A Threshold Selection Method from Gray-Level Histograms, IEEE Trans. Syst. Man. Cybern. 9 (1979) 62-66.

[86] L. He, X. Ren, Q. Gao, X. Zhao, B. Yao, Y. Chao, The connected-component labeling problem: A review of state-of-the-art algorithms, Pattern Recognit 70 (2017) 25-43.

[87] C.L.A. Leung, R. Tosi, E. Muzangaza, S. Nonni, P.J. Withers, P.D. Lee, Effect of preheating on the thermal, microstructural and mechanical properties of selective electron beam melted Ti-6Al-4V components, Mater. Des. 174 (2019) 107792. 